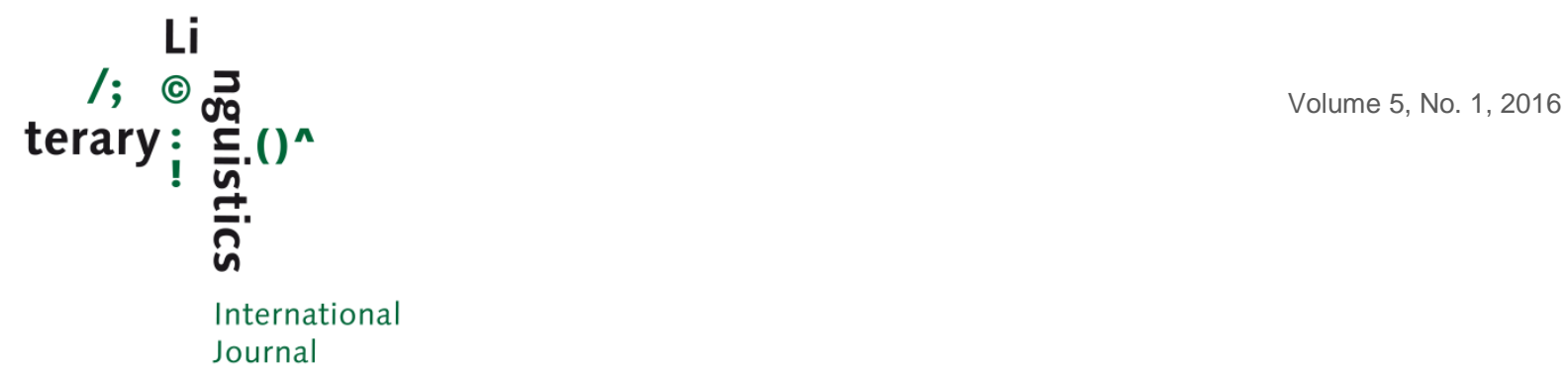

\title{
Metaphors we may not live by
}

\author{
David L. Hoover
}

Keywords:

Metaphor, conceptual metaphors, corpus linguistics, COCA
Abstract: Metaphors We Live By created an immediate stir in 1980, and it continues to spur interest in cognitive linguistics, cognitive stylistics, and metaphor theory. This article uses both collocations and random samples of words used in conceptual metaphors to search for corpus evidence of the pervasiveness of conceptual metaphor that was unavailable to Lakoff and Johnson. Some metaphors, such as TIME IS MONEY, are pervasive in giant natural language corpora. Others, such as MORE IS UP, are frequent in clearly and consciously metaphorical forms, but relatively rare in the basic forms that would clearly show that we use metaphor to understand more abstract concepts in terms of concrete ones. Some, including ARGUMENT IS WAR, that Lakoff and Johnson discuss throughout their book, are poorly represented. Some gaps in evidence probably result from multiple ways of expressing a complex conceptual metaphors, but others suggest that intuitive plausibility is an insecure basis for argument.

\section{Introduction}

When Lakoff and Johnson published Metaphors We Live By in 1980, it created an immediate and deserved stir, and its legacy continues to expand in the areas of cognitive linguistics, cognitive stylistics, and cognitive metaphor theory. Many of the metaphors discussed in the book seem as powerful and persuasive as they did thirty-five years ago. The real-world physical origins of MORE IS UP still seem completely convincing: more is up because large amounts make piles (16). The basis of the metaphor is gravity and physics. Language is the way it is partly, perhaps even largely, because the world and people are the way they are. Front/back and left/right, for example, would make little sense to entirely symmetrical creatures with eyes and limbs all around a spherical body. The importance of the fact that cognition is embodied seems undeniable, as does the significance of the nature of that embodiment (Johnson 1987), and the cognitive turn has been especially important in stylistics (for example, Lakoff and Turner 1989; Emmott 1997; Fauconnier and Turner 2002; Semino and Culpeper 2002; Gavins and Steen 2003). We now even seem poised to be able to study the actual mechanisms of cognition (Starr 2013). Rather than discussing these and other important developments, however, here I want to go back to Metaphors We Live By and ask some questions about the ubiquity and centrality of conceptual metaphor that have only become answerable since the advent of huge electronic corpora. 
The argument for TIME IS MONEY / A VALUABLE COMMODITY / A LIMITED RESOURCE, like MORE IS UP, also still seems compelling. In our culture work is typically paid for on the basis of duration, so that we have become especially likely to see time itself as valuable, as capable of being spent, saved, or wasted. The metaphor clearly predates payment by the hour, however, as shown by the following comments by the Host from the introduction to The Man of Law's Tale in Chaucer's Canterbury Tales (ca. 1386):

Lordynges, quod [said] he, I warne yow, al this route [company],

The fourthe party of this day is gon.

Now, for the love of God and of seint john,

Leseth [lose] no tyme [time], as ferforth as [as far as] ye may.

Lordynges, the tyme wasteth nyght and day,

And steleth [steals] from us, what pryvely [privately] slepynge,

And what thurgh necligence in oure wakynge,

As dooth the streem that turneth nevere agayn,

Descendynge fro the montaigne into playn.

Wel kan [can] senec [Seneca] and many a philosophre

Biwaillen tyme moore than gold in cofre;

For-los of catel [possessions] may recovered be,

But los of tyme shendeth [destroys] us,-quod [said] he.

The Host's invocation of Seneca suggests that the metaphor of TIME IS A VALUABLE COMMODITY / LIMITED RESOURCE is much older still, and it has always seemed to me that Lakoff and Johnson paid too little attention to the implications of their theory for language history. If they are right about how central our use of metaphor is in helping us understand the abstract with respect to the concrete, TIME IS A VALUABLE COMMODITY / LIMITED RESOURCE presumably predates money. Unfortunately, the fact that the earliest records of language reflect hundreds of thousands of years of language use precludes anything resembling a proof of their theory.

When considering the compelling examples of conceptual metaphor that Lakoff and Johnson present, however, we can now do what they could not easily do in 1980-we can test the prevalence of these metaphorical mappings in huge natural language corpora like Mark Davies's 450 million word Corpus of Contemporary American English (Davies 2008-; COCA, below). Although COCA covers a slightly later period (1990-2012) than the examples presented by Lakoff and Johnson and is mostly written rather than spoken, it seems an appropriate testing ground for my purposes. The fact that COCA contains more recent language seems unproblematic because Lakoff and Johnson are committed to the idea that the conceptual metaphors they discuss are persistent rather than transient. The fact that only twenty percent of the corpus is spoken should not pose serious problems either. While Lakoff and Johnson typically use as examples sentences that seem more likely to be spoken than written, their central claim that "Our ordinary conceptual system . . . is fundamentally metaphorical in nature" (3) surely commits them to the presence of their cognitive metaphors in writing as well as speech. (To address this issue, I will, 
at several points below, compare the spoken part of COCA with the fiction, magazine, newspaper, and academic parts.)

\section{Corpus evidence and some important conceptual metaphors}

\subsection{Is MORE really UP?}

First, a glance back at MORE IS UP. Perhaps surprisingly, more, less, increase, and decrease do not collocate significantly with up and down, in COCA. In fact, all of these collocations have negative mutual information scores, showing that more, less, increase, and decrease are actually found less frequently than would be expected by chance within nine words left or right of up and down. A span of nine words is longer than is usually used in studies of collocation, but a more typical span of four or five words identifies many more collocations of very rare words, and the longer span should also capture metaphor better than a shorter one would. (For a discussion of collocations of various spans, including some much longer than nine words, in stylistics and authorship attribution, see Halliday and Hasan 1976: 294-59, 330-31 and Hoover 2003.) The mutual information score (MI score, below) measures how frequently two words appear near each other, taking into account how frequently this would happen by chance, based on the frequencies of the words and the size of the corpus. In COCA, the MI score is calculated as follows (Davies 2008):

$\mathrm{MI}=\log \left(\left(\#\right.\right.$ co-occurrences* ${ }^{*}$ corpus size) / (node

freq. ${ }^{*}$ collocate freq. ${ }^{*}$ total span)) / $\log (2)$

The metaphor MORE IS UP is certainly present in the corpus, but the negative MI scores of more, less, increase, and decrease with up and down show that it is not typically expressed in these most basic terms. And, however natural it seems to talk about price, prices, temperature, and temperatures going up or down, these words also fail to collocate very strongly with up and down:

$\begin{array}{lll}\text { Word } & \text { Collocate } & \text { MI Score } \\ \text { price } & \text { up } & 0.12 \\ \text { prices } & \text { up } & 0.77 \\ \text { price } & \text { down } & 0.41 \\ \text { prices } & \text { down } & 1.36 \\ \text { temperature } & \text { up } & 0.17 \\ \text { temperatures } & \text { up } & -0.22 \\ \text { temperature } & \text { down } & 0.20 \\ \text { temperatures } & \text { down } & 0.11\end{array}$

Perhaps because decreased prices seem more worthy of comment, prices collocates with down at the highest level among these words, but a minimum MI score of three is typically required for a collocation to be considered solidly established, and none of these collocations comes even close to that level. In 
fact, down ranks only $3,718^{\text {th }}$ among the collocates of prices. Note that all of these collocations are somewhat more frequent in the spoken part of COCA (prices and down collocate with an Ml score of 2.45 there), suggesting that perhaps the more basic forms of the metaphor are more likely to be found in less formal contexts. All of these collocations have even lower MI scores in Davies's historically-based Corpus of Historical American English (Davies 2010), many of them negative, showing that it is unlikely that the low scores are a result of language changes in the last thirty-five years.

Unfortunately, because of the way it is calculated, the Ml score is very sensitive to chance collocations of rare words. Of about 1,600 collocates of prices with MI scores of three or more, about 500 appear only twice, and more than 900 appear fewer than six times in the entire 450 million word corpus. Such words hardly seem like significant collocates. However, of the 627 collocates with MI scores of three and frequencies of at least six, at least 100 clearly express the MORE IS UP metaphor. It is difficult to know how much metaphor to consider significant, but surely a ratio of more than one in seven highly significant collocates is evidence of a strong presence of this orientation metaphor in Modern English.

Consider, however, the twenty collocates of prices with the highest MI scores among these 100:

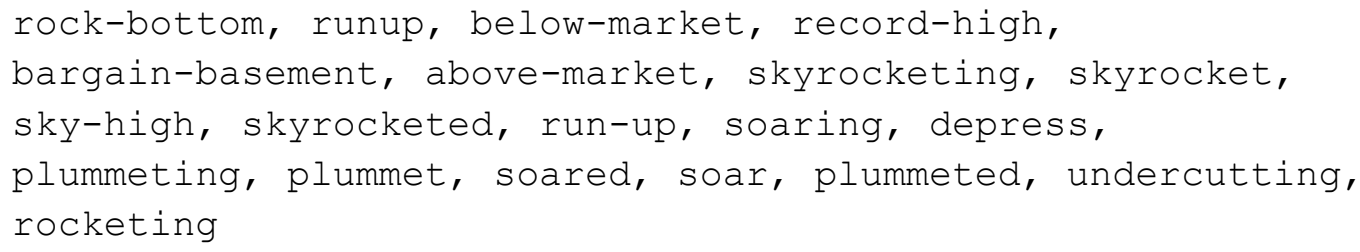

A few of these are basic and relatively banal, but it seems striking how clearly and emphatically metaphorical most of them are. Prices can be below-market or above-market, but they more frequently soar, skyrocket, rocket, and plummet, emphasizing and exaggerating the directionality of MORE IS UP and suggesting a secondary metaphor of PRICES ARE FLYING OBJECTS, as well. It also seems fair to say that this secondary metaphor tends to conflict with the physical and gravitational basis of MORE IS UP. Thus the metaphor is wellattested, but the most salient examples seem artful, consciously metaphoric, and not very basic, while the basic forms are not very common. The last twenty of the collocates with $\mathrm{MI}$ scores of at least three tend to be somewhat more normal or basic, though most of these also seem to emphasize movement upward rather than piling up:

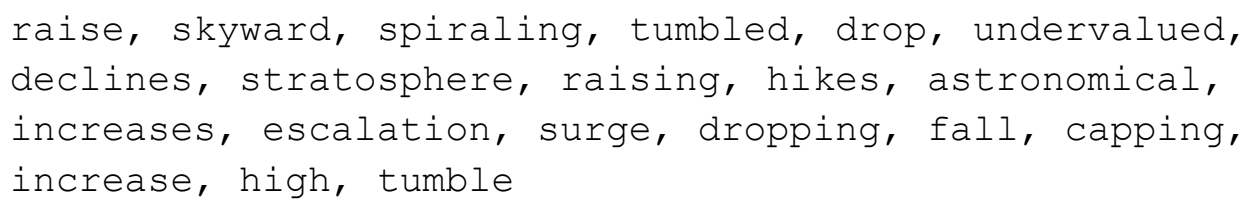


Considering the argument that Lakoff and Johnson make for the basic nature of metaphor in language and their insistence that we use metaphor to understand more complex or abstract concepts in terms of simpler, more concrete ones, these findings seem surprising.

\subsection{TIME IS MONEY}

Now, let us return to consider TIME IS MONEY / A VALUABLE COMMODITY / A LIMITED RESOURCE. Here, the corpus evidence from COCA is overwhelming. We do indeed seem to conceive of time very frequently in these metaphorical ways (although the Ml score for the collocation of money itself with time is only 0.27 ). There are only thirty-nine collocates for time in COCA with a mutual information score of three or more within a span of nine words before or after time. Their frequencies range from 32 to 13,106. Of these thirty-nine, at least eight clearly exemplify the metaphorical meaning (in descending frequency order): spend, spends, wasting, wasted, devote, allotted, elapsed, and devoting. In addition, inordinate also suggests a valuable commodity, and, in context, most of its examples also involve a form of spend. In addition to having high $\mathrm{MI}$ scores, these nine words are frequent enough to account for more than half $(19,271)$ of all the occurrences of collocates of time with Ml scores greater than three. Other collocates, such as totaltime, marinating, prep, and minutescooking (all from recipes), in context also exemplify TIME IS A VALUABLE COMMODITY. In this case, corpus evidence solidly confirms the claim of Lakoff and Johnson that we very frequently and centrally conceive of time as money, as a valuable commodity, or as a limited resource.

\subsection{ARGUMENT IS WAR}

But not all of the metaphors that Lakoff and Johnson discuss are so well attested. For example, one of their most famous examples, one that runs through the entire book, is ARGUMENT IS WAR, corrected to ARGUMENT IS STRUGGLE in the "Afterword" of the 2003 edition. They argue that our ordinary way of structuring or having an argument is in terms of the ARGUMENT IS STRUGGLE metaphor (5) and later provide an extended discussion of CONVERSATION and ARGUMENT and the ARGUMENT IS STRUGGLE metaphor (77-86). This is an important social and political issue for Lakoff and Johnson:

Our conventional ways of talking about arguments presuppose a metaphor we are hardly ever conscious of. The metaphor is not merely in the words we use-it is in our very concept of an argument. The language of argument is not poetic, fanciful, or rhetorical; it is literal. We talk about arguments that way because we conceive of them that way-and we act according to the way we conceive of things. (5) 
If this were true, it would be reasonable to expect the ARGUMENT IS STRUGGLE metaphor to be well-attested in corpora, and the same is true of the other metaphors they mention for argument: ARGUMENT IS A JOURNEY / BUILDING / CONTAINER. However, among the 100 collocates of argument with the highest mutual information scores in COCA (all above three; minimum frequency of five), counting generously, I find only the following (as will be seen below, in some cases plural and singular words have substantially different collocates, but the collocates of arguments are quite similar to those of argument):

$\begin{array}{ll}\text { BUILDING } & 6 \\ \text { WAR/STRUGGLE } & 5 \\ \text { CONTAINER } & 1 \\ \text { JOURNEY } & 0\end{array}$

Compare these with other highly significant collocations:

$\begin{array}{ll}\text { Evaluative } & 20 \\ \text { Proper Names } & 13 \\ \text { Argument-Specific } & 12 \\ \text { PERSON } & 10 \\ \text { Legal } & 5\end{array}$

The most prevalent collocates are evaluative, and most of the words are tied rather closely to the nature of arguments and not obviously metaphorical (words like specious, fallacious, fallacy, cogent, plausible, implausible, valid). Overlapping with the 'evaluative' category is relatively specialized vocabulary from the semantic field of argument (words like refutation, crux, argument, refuted, refute, rhetorical, gist, inference, premise, arguments). Another frequent category is 'proper names.' These three categories, along with the category 'legal,' containing rebuttal, closing, oral, appellate, and briefs, account for fifty of the 100 most significant collocates. A group of ten other collocates from the 100 might support AN ARGUMENT IS A PERSON, although these collocates could also be included in the argument-specific or evaluative groups: self-referencing, persuasive, unconvincing, convincing, credence, disingenuous, self-serving, persuasion, principled, rational. The figures for the spoken part of COCA alone are very similar to the overall figures, except for the category of "legal," which is, perhaps surprisingly, considerably higher in the spoken part.

The totals I have given for the collocates that support the metaphors that Lakoff and Johnson discuss also include examples that are not very clear-cut:

BUILDING: undercuts, bolster, bolstered, undermines, rests, reinforces

WAR/STRUGGLE: brooked, compelling, heated, escalated, raged CONTAINER: nutshell 
None of the BUILDING collocates of argument above appears among the collocates of building itself with a frequency of at least ten and an MI score of at least three, and none of these words is limited to the semantic field of 'buildings.' Only escalated and raged from the WAR/STRUGGLE list above appear among the collocates of war itself with a frequency of at least ten and an $\mathrm{MI}$ score of at least three. Escalates does collocate with struggle with an MI score of more than three, and escalate, escalated, escalating, rages, raging, and raged all collocate with struggle with an MI score of more than two. Yet, if our ordinary way of structuring our understanding of an argument is as a struggle, it seems surprising that such a low proportion of the strong collocates of argument relate to 'struggle.'

An alternative way of testing the strength of ARGUMENT IS STRUGGLE is to take a random sample of examples of argument and examine them for the metaphor. This should capture some collocations beyond the nine-word limit left and right, and should also uncover instances of the metaphor that are exemplified by multiple but individually infrequent words. Here are the only examples I could find in a random sample of 200 occurrences of argument in COCA:

1. But some of the grand old sparring partners in this argument are actually pretty sanguine.

2. Given the thrust of the argument advanced in "Dictatorships and Double Standards"

3. But Asian member states protested and won the argument, contending

4. ignoring everything they do can leave their best argument unchallenged.

5. reported there was also a heated argument between ... Faisal and ... Tariq Aziz

6. any seemingly defensible argument concerning how they might be represented

7. The argument escalated ... when his friend began pummeling him with a racquetball

There is certainly room for disagreement here, but I do not find numbers two and five very clear examples of ARGUMENT IS STRUGGLE. In any case, however, the presence of seven instances of the metaphor in 200 examples does not seem to support the basic and ubiquitous nature Lakoff and Johnson claim for ARGUMENT IS STRUGGLE.

Consider the related claim that Lakoff and Johnson make that the ordinary way to talk about "attacking a position" in an argument is to use those very words (5). On the contrary, we find that only attacking (with an Ml score of 0.57 and a frequency of twenty-three), attacked (with an MI score of 0.41 and a frequency of thirty-seven), and counterattack (with an MI score of 1.37 and a frequency of four) occur as collocates of position in COCA with MI scores of 0.1 or higher and a minimum frequency of three. The words attacking and attacked also collocate 
with argument, but with even smaller MI scores and lower frequencies. Finally, checking all verbs that collocate with argument (minimum MI score of one; minimum frequency of three) and limiting ourselves to those with a negative meaning, to parallel attack, we find only the following examples with an Ml score of at least three:

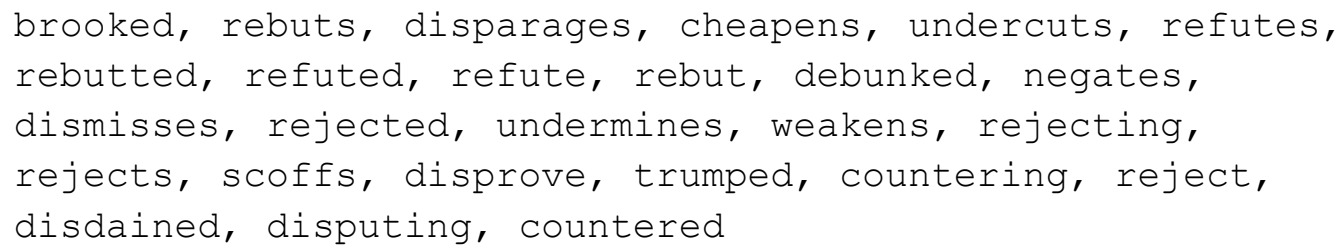

These words would hardly lead anyone to suggest ARGUMENT IS STRUGGLE. If we really do use the more concrete STRUGGLE to shape our understanding of the more abstract 'argument,' it is puzzling that the metaphor is so weakly represented in this huge corpus. In spite of the intuitive persuasiveness of the idea that an argument is a kind of verbal struggle one can win or lose, and in which one takes positions, defends them, and attacks the other participant's positions, there is surprisingly little evidence that "attacking a position or argument" is the ordinary or usual way of rebutting or rejecting one, or that we normally think of arguments in terms of struggles, buildings, or containers.

\subsection{The CONDUIT metaphor for language}

I turn, now, to the complex CONDUIT metaphor that Lakoff and Johnson (10-13) cite from Michael Reddy:

\section{IDEAS (OR MEANINGS) ARE OBJECTS. LINGUISTIC EXPRESSIONS ARE CONTAINERS. COMMUNICATION IS SENDING}

Lakoff and Johnson cite locutions like "get the idea across to someone," "give someone an idea," "put an idea into words," "your reasons came through to us," "pack more thought into fewer words," "the meaning is right there in the words," and so forth (11). Later in the book, they argue that the "Objectivist Theory of Communication," which they reject, is a version of the CONDUIT metaphor (206-09). (For an argument against the CONDUIT metaphor on rather different grounds see Harris 1981, 2010.) As a first test of the ubiquity of this metaphor, I checked how significantly the prepositions in, into, across, and through collocate with singular and plural forms of idea, meaning, thought, reason, word, sentence, and paragraph, and averaged the MI scores for the collocations of these fourteen forms of 'idea' words with each preposition. The average MI score is negative for all four prepositions: these directional prepositions appear near the 'idea' words less often than they would by chance. Only seventeen of the fifty-six collocations show positive MI scores, and the highest of these, for the collocation of through with meanings, is quite weak, at 0.78 . 
Next, I tested all forms of the following words that Lakoff and Johnson italicize in their examples of the CONDUIT metaphor as collocates of idea/ideas: burry, capture, carry, come, content, force, get, give, hollow, pack, put, receive, send, stuff, take, and without (11). I examined all the collocations for which the MI score was greater than one (about 4,500), but only the following forms of the words are among these (the form of idea with which the word collocates is in parentheses):

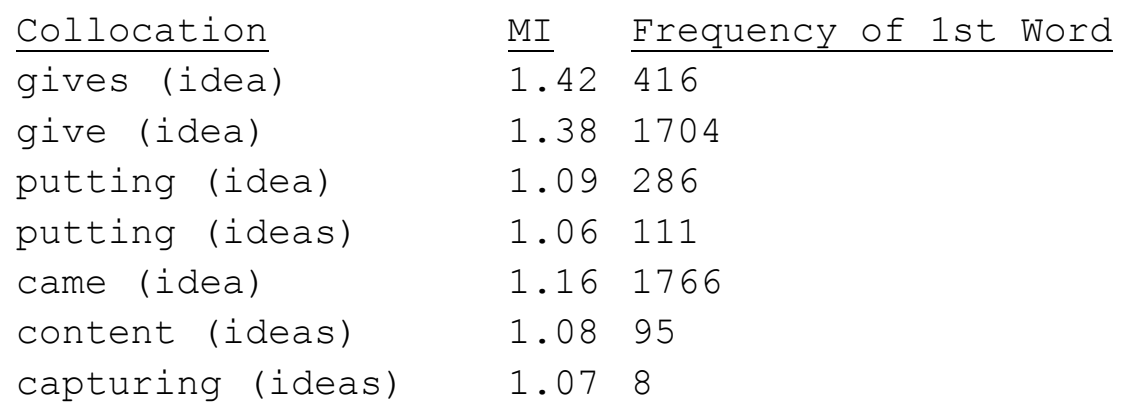

Clearly, there is a relationship here, but just as clearly it is not a very strong one: collocations of forms of most of the sixteen words I have taken from the examples that Lakoff and Johnson give either are nonexistent in the corpus or have MI scores below one. I did find a few stronger MI scores among words that contain forms of the words above (all of which are less frequent than the forms they contain):

\begin{tabular}{llll} 
Collocation & MI & Frequency of 1st Word \\
\cline { 2 - 3 } repackage (ideas) & 4.78 & 4 \\
repackaged (ideas) & 3.09 & 2 \\
input (ideas) & 1.83 & 38 \\
take-away (ideas) & 5.32 & 4 \\
note-taking (ideas) & 3.26 & 2 \\
undertakings (ideas) & 2.46 & 3
\end{tabular}

Unlike the more basic forms cited by Lakoff and Johnson, these all collocate with the plural rather than the singular, and most seem more specific than the CONDUIT metaphor.

Examining 200 random examples each of idea and ideas suggests that this pattern is more general: only about one third of the singular examples are metaphoric, while half of the plural examples are. (For a similar distinction between the collocates of a plural and singular noun, but more pronounced and in the opposite direction, see John Sinclair's discussion of eye/eyes (2003: 16772). For ideas, the CONDUIT metaphor is quite prevalent: nearly forty of the 200 examples exemplify it. Among the other metaphors for ideas that Lakoff and Johnson mention (46-48), IDEAS ARE ORGANISMS is represented by seventeen of the 200 examples and IDEAS ARE COMMODITIES is represented by fifteen. IDEAS ARE BUILDINGS is weakly represented by three examples, but I have not found any clear examples of IDEAS ARE FOOD, IDEAS ARE 
RESOURCES, IDEAS ARE MONEY, IDEAS ARE CUTTING INSTRUMENTS, or IDEAS ARE FASHIONS.

The picture is quite different for idea. As noted above, the proportion of metaphoric uses is substantially lower (there are just ten CONDUIT and nine COMMODITIES examples in the 200 random examples of idea, and a smattering of other metaphors). By far the most interesting collocate of idea in this group of examples is the idiom 'have no idea' (including a few closely related locutions involving "the slightest/haziest/any idea"), which is found in thirty-three of the examples. Perhaps one could argue that IDEAS ARE OBJECTS is implicated in 'have no idea,' so that these count as examples of the CONDUIT metaphor, but that seems implausible. Not having an idea seems to preclude transferring one through a conduit. Nearly thirty more of the examples are evaluative and non-metaphorical. As we saw with MORE IS UP and ARGUMENT IS STRUGGLE, the CONDUIT metaphor is better represented by more obviously metaphorical examples than with the simple, basic ones. (A quick check of 100 random examples of ideas in the spoken part of COCA shows about the same proportions of the various metaphors.)

\subsection{THE MIND IS A BRITTLE OBJECT / A MACHINE}

For my last example, I turn to the discussion by Lakoff and Johnson of two ontological metaphors for the mind (along with their examples):

\section{THE MIND IS A BRITTLE OBJECT}

Her ego is very fragile.

You have to handle him with care since his wife's death.

He broke under cross-examination.

She is easily crushed.

The experience shattered him.

I'm going to pieces.

His mind snapped. (28)

This is an unpersuasive set of metaphors for the mind. All of these except the last seem to be metaphors for the whole person, the emotions, or perhaps the will (for the example with broke) ${ }^{1}$.

\section{THE MIND IS A MACHINE}

We're still trying to grind out the solution to this equation.

My mind just isn't operating today.

Boy, the wheels are turning now!

I'm a little rusty today.

\footnotetext{
${ }^{1}$ For a nice example of the use of break to express THE MIND IS A BRITTLE OBJECT, see the lyrics of Kenny Rogers's 1968 hit song "I Just Dropped in (to See What Condition My Condition Was In)," in which the speaker says, "I saw so much I broke my mind," though rather incoherently, or psychedelically, as earlier in the song he says, "I tore my mind on a jagged sky." This example is clearly intentionally artful and striking and anything but basic.
} 
We've been working on this problem all day and now we're running out of steam. (27)

This metaphor also seems somewhat mixed, and is only partly about minds. The last example seems to figure the entire person as a machine, not the mind, and the example with rusty could just as easily be about some physical skill, rather than a mental one (to me it seems more natural referring to a physical skill). ${ }^{2}$ Lakoff and Johnson note that these two metaphors focus on different aspects of mental experience:

He broke down. (THE MIND IS A MACHINE)

He cracked up. (THE MIND IS A BRITTLE OBJECT) (28)

It is worth quoting an extended comment that highlights just how centrally they see such metaphors:

Ontological metaphors like these are so natural and so pervasive in our thought that they are usually taken as self-evident, direct descriptions of mental phenomena. The fact that they are metaphorical never occurs to most of us. We take statements like "He cracked under pressure" as being directly true or false. This expression was in fact used by various journalists to explain why Dan White brought his gun to the San Francisco City Hall and shot and killed Mayor George Moscone. Explanations of this sort seem perfectly natural to most of us. The reason is that metaphors like THE MIND IS A BRITTLE OBJECT are an integral part of the model of the mind that we have in this culture; it is the model most of us think and operate in terms of (28-29).

Perhaps A PERSON IS A BRITTLE OBJECT is an integral part of our model of human beings, but there is very little evidence that we conceive of minds in this way. Among the 600 most significant collocates of mind (MI score of one or higher) there are none that suggest THE MIND IS A BRITTLE OBJECT. Also, minds don't tend to snap, crack, or break very often: no forms of these words collocate significantly with mind.

Perhaps surprisingly, THE MIND IS A MACHINE is also rather poorly represented in COCA. Among the seventy-four collocates of mind with an MI score of at least three and a minimum frequency of ten, there are only five (in descending MI score order) that suggest THE MIND IS A MACHINE: one-track, replaying, replayed, workings, picturing. (The spoken part of the corpus does not show any increase in THE MIND IS A MACHINE metaphor.) Furthermore, only three of the twenty-six examples involving picturing involve the mind doing the picturing; the others are almost all examples of the idiom of 'picturing something in the mind,' in which the mind is more reasonably considered a container. The same is true of replaying, in which only seven of thirty-five

${ }^{2}$ For an excellent discussion of THE PERSON/MIND IS A MACHINE in Ken Keesey's One Flew Over the Cuckoo's Nest, see Semino and Swindlehurst (1996: 147-57). 
examples involve the mind as an actor, and replayed, in which only ten of fortyfour do so. Although one-track is the second most significant collocate of mind, with an Ml score of 7.1, the phrase one-track mind is an idiom, and mind is the only collocate of one-track with an MI score above three. Such fixed idioms seem related to "dead" metaphors, like "the foot of the mountain," and so do not offer much support for the argument of Metaphors We Live By (see 54-55 on "dead" metaphors).

Clearly, we can think of a mind as a machine, and new examples are easily interpretable and often striking, as in this example from a memoir:

By then my father had tugged himself up by the ropes of his muscles and the pulleys of his mind to where he could take charge of a season, generally summer (Doig 1993).

Clearly this metaphor is one of the ways we can think about minds. But it again seems to be consciously artful and metaphorical (to my ear, also rather forced) and lacks the centrality that Lakoff and Johnson suggest.

The most salient metaphors for mind, as revealed by its seventy-four most significant collocates (with MI scores of at least three and a minimum frequency ten), are these (the total number of collocates representing the metaphor in parentheses):

THE MIND IS A PERSON/ORGANISM (20): boggles, boggling, boggle, boggled, inquiring, impressionable, wanders, inquisitive, wander, reeled, conjured, raced, dwelt, conjures, wandered, preying, agile, depraved, omniscient, wandering .

I was surprised that four of the five most significant collocates of mind are forms of the verb boggle (the other, as noted above, is one-track), exemplifying the idiom of the mind 'boggling' or 'being boggled' (only mind, minds, imagination, brain, and stuff collocate with a minimum Ml score of about three with forms of boggle).

THE MIND IS A CONTAINER (9): conjured, conjures, doubt, thoughts, keep, borne, bear, beholder, bearing.

Forms of conjure sometimes fit here and sometimes fit above. That is, the mind (as a PERSON) sometimes conjures things, but a person may also conjure (up) things in his or her mind (CONTAINER). Lakoff and Johnson also mention this metaphor (148).

THE MIND IS A LOCATION (8): uppermost, furthest, unbidden, flitted, flashed, crossed, forefront, foremost. 
Two additional examples might fit either here, in CONTAINER, or in a more marginal related metaphor, THE MIND IS A ROOM: recesses and uncluttered.

THE MIND IS A WRITING SURFACE (7): indelibly, tabula, imprinted, rasa, etched, indelible, blank

Expanding the search for metaphorical collocates by reducing the minimum frequency to five and the minimum $\mathrm{Ml}$ score to two reveals many further examples of the metaphors above, and uncovers one I was expecting to see earlier: THE MIND IS A CUTTING TOOL: keenest, sharpens, sharpest, incisive, razor-sharp, sharpen, keen, sharper. There is a substantial amount of metaphor here, but the particular metaphors Lakoff and Johnson intuitively think are central are relatively marginal, and other more frequent metaphors are revealed by a corpus study.

\section{Conclusion}

The discussion above does not, of course, prove that we do not use conceptual metaphors to help us understand the abstract and intangible, but it does provoke some interesting questions and suggest that more empirical, datadriven research is needed if we are to accurately assess the place and significance of conceptual metaphor in language. If a given metaphor is not very prevalent in our language, why does an argument for it seem so persuasive when we read it? The simplest answer is that we are all metaphor machines, so that even a novel metaphor is generally comprehensible. Or, to put it more precisely, a unique and novel metaphor is often both immediately comprehensible and also striking and memorable, as many great poets have understood. Take for example Gerard Manley Hopkins's treatment of 'mind' in the sestet of his "terrible" sonnet "No Worst, There is None":

O the mind, mind has mountains; cliffs of fall

Frightful, sheer, no-man-fathomed. Hold them cheap

May who ne'er hung there. Nor does long our small

Durance deal with that steep or deep. Here! creep,

Wretch, under a comfort serves in a whirlwind: all

Life death does end and each day dies with sleep.

Another significant question is whether or not the metaphoric structuring is somehow "there" in the data but in a form that is not discovered by studying collocations. This seems likely in some cases, especially for some of the subtler and more complex examples given by Lakoff and Johnson. For example, a wide range of vocabulary can exemplify LOVE IS A PHYSICAL FORCE (49), so that any given word may not collocate strongly enough to be a significant collocate in itself. This is the reason for testing the metaphors against random sets of examples above, but even that method does not necessarily catch examples in which the central concept (here LOVE) is not explicitly expressed. No forms of any of the words Lakoff and Johnson italicize in their examples of LOVE IS A 
PHYSICAL FORCE collocate with love with an MI score even as high as 0.5 , but this does not mean that no forms of these words are used in talking about love. The word attractive, a relative of the attracted of their example, is such a prevalent way of describing a desirable love-interest that it seems unlikely that most speakers think of the metaphor of magnetism or gravity when they use it. (The idea that magnetism and gravity are more readily understood than love also seems problematic.) Here are the twenty most significant collocates of attractive (minimum frequency of ten; MI scores ranging from 6.64 to 4.19), in descending Ml score order:

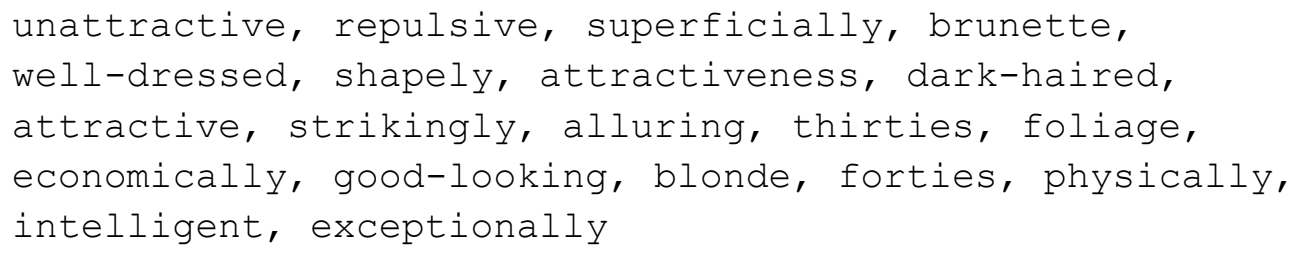

The connection with love is obvious here, and only foliage and economically are obviously not related to love. Yet only physically and possibly strikingly might be connected to LOVE IS A PHYSICAL FORCE. The fact that the opposites unattractive, repulsive and the limiter superficially are the most significant collocates surprised me, as did the order of brunettes and blonde, violating a common stereotype. And intelligent people in their thirties and forties can take heart (though perhaps these collocates are salient because attractiveness is conceived as remarkable for them).

In the spoken part of COCA, the twenty strongest collocates of attractive (with a minimum frequency of seven, MI scores ranging from 7.38 to 3 , in descending $\mathrm{MI}$ order) are somewhat different, though they also lack any significant evidence of LOVE IS A PHYSICAL FORCE:

attractive, articulate, buyers, sexy, appealing, attracted, bonds, stocks, option, compelling, bright, intelligent, alternative, sexually, smart, less, young, rates, investment, women

The most obvious difference between this list and the list from the whole corpus is the much larger number of words related to investments.

While gravitated, another word from an example given by Lakoff and Johnson, has no significant clearly love-related collocates, about ten percent of the examples of gravitated toward are clearly related to love. One of their other examples is "The atmosphere around them is always charged." Atmosphere also lacks love-related collocates, and only about four percent of the examples of the collocation of atmosphere and charged are related to love. Lakoff and Johnson give some examples that mention marriage, and I expected healthy marriage, in particular, to be a common collocation. Instead, marriage has no health-related collocates with an $\mathrm{Ml}$ score above three and healthy marriage has an $\mathrm{Ml}$ score of only 1.18 . Clearly more work is needed on ways of locating 
conceptual metaphor in corpora, especially in cases where a metaphor has a large number of possible expressions. Just as clearly, it is dangerous to rely on our intuition in discussing the prevalence or significance of metaphors.

Why do corpora strongly confirm some metaphors but not others? It is possible that better methods might find additional evidence for metaphors like ARGUMENT IS STRUGGLE. However, it is difficult to see why this case would be like LOVE IS A PHYSICAL FORCE, and many of the examples presented by Lakoff and Johnson explicitly include the word argument. In this and some other cases, it seems more likely that the strength of the metaphor has simply been overstated. After all, it was too much to expect the intuitions of Lakoff and Johnson about which metaphors are important to be right all the time. In addition to a differential in how significant conceptual metaphors are, however, one likely factor is how complex the underlying concept is. In TIME IS MONEY, money is a relatively simple concept, with fairly limited range and semantics, so that the metaphor is more likely to use the same words that collocate with money. What we do with money seems relatively restricted, although the depressing fact that launderers, laundering, launderer, and extort are among the top ten collocates of money reveals that not everyone obeys all of those restrictions. Obviously, none of these verbs works well with time. (Perhaps some of us have "laundered" our time by lying about how we spent it.) For the CONDUIT metaphor, in contrast, as for LOVE IS A PHYSICAL FORCE, the source domain of the metaphor is more complex, and there are myriad ways of expressing it, so that searching for examples is more challenging. Whatever the challenges may be, however, it seems crucial to find ways of using huge corpora to guide and inform our understanding of conceptual metaphor and how it works in (the English) language.

\section{References}

Davies, Mark (2008). The Corpus of Contemporary American English: 450 million words, 1990-present, 5 January 2015. http://corpus.byu.edu/coca/.

Davies, Mark (2010). The Corpus of Historical American English: 400 million words, 1810-2009, 5 January 2015. http://corpus.byu.edu/coha/.

Doig, Ivan (1993). Heart Earth. New York: Maxwell Macmillan International. (Taken from COCA.) 5 January 2015.

Emmott, Catherine (1997). Narrative Comprehension: A Discourse Perspective. Oxford: Oxford University Press.

Fauconnier, Giles \& Mark Turner (2002). The Way We Think: Conceptual Blending and the Mind's Hidden Complexities. New York: Basic Books.

Gavins, Joanna \& Gerard Steen, Eds. (2003). Cognitive Poetics in Practice. London: Routledge.

Halliday, M. A. K. \& Ruqaiya Hasan (1976). Cohesion in English. Harlow: Longman.

Harris, Roy (1981). The Language Myth. London: Duckworth. 
Harris, Roy (2010). Language Myths, East and West, Integrationist Notes and Papers 2009-2011. Gamlingay: Bright Pen.5 January 2015. http://www.royharrisonline.com/INP26.html.

Hoover, David L. (2003). Frequent Collocations and Authorial Style, Literary and Linguistic Computing, 18(3): 261-86.

Johnson, Mark (1987). The Body in the Mind: The Bodily Basis of Meaning, Imagination, and Reason. Chicago: University of Chicago Press.

Kesey, Ken (1962). One Flew Over the Cuckoo's Nest. New York: Viking Press.

Lakoff, George \& Mark Johnson (2003 [1980]). Metaphors We Live By. Chicago: University of Chicago Press.

Lakoff, George \& Mark Turner (1989). More than Cool Reason: A Field Guide to Poetic Metaphor. Chicago: University of Chicago Press.

Reddy, Michael (1979). The Conduit Metaphor. In A. Ortony, ed. Metaphor and Thought. Cambridge: Cambridge University Press.

Semino, Elena, \& Jonathan Culpeper, Eds. (2002). Cognitive Stylistics: Language and Cognition in Text Analysis. Amsterdam: Benjamins.

Semino, Elena \& Kate Swindlehurst (1996). Metaphor and Mind Style in Ken Kesey's One Flew Over the Cuckoo's Nest, Style 30(1): 143-66.

Sinclair, John (2003). Reading Concordances: An Introduction. London: Pearson Longman.

Starr, G. Gabriel (2013). Feeling Beauty: The Neuroscience of Aesthetic Experience. The MIT Press. 